\title{
19 | Exploring food and farming futures in Zimbabwe: a citizens' jury and scenario workshop experiment
}

\author{
ELIJAH RUSIKE
}

Much debate about the future of agriculture and what technologies are appropriate is very narrowly framed. Discussions often assume that scientists know what is best and that technology users are simply involved in processes of adaptation and fine tuning. But is this enough? With major changes in the contexts for agricultural livelihoods unfolding across the developing world, setting priorities for agricultural technology development and policy more generally is becoming more challenging. There are a range of new needs associated with changing patterns of labour availability, land pressure, opportunities for off-farm work and health conditions.

Yet technology trajectories are often implicitly imposed. For example, the debate about genetically modified (GM) technologies in the developing world has very often been limited to discussions about the health or environmental risks of one or other GM crop. But the implications of a move towards a more industrialized, commercialized and transnationaldependent agriculture are hidden from view in mainstream regulatory and policy deliberations. GM, however, some argue, entails fundamental changes in the agri-food system, and with this changes in food rights and sovereignty, with major ramifications for people's livelihoods

Given the controversial nature of such new technologies and the farreaching implications of their adoption, approaches to discussion and deliberation are needed which expand the horizons of debate in terms of scope, content and participants. Such issues, which impinge on the longterm possibilities for livelihoods and ways of living, are not just technical discussions about risk and regulation, but are about the type of future a society wants, with implications for rights and justice, particularly for those who are potentially going to be marginalized by such changes. This requires a coming together of a wide group of stakeholders - scientists, bureaucrats, campaign groups, ordinary consumers and the diversity of producers - to open up debate and suggest options. 


\section{Citizens' juries}

Citizens' juries have become one of a number of 'deliberative inclusionary processes' which have been experimented with over the past decade or so in response to such challenges. Along with scenario workshopping, future search, consensus conferences, constructive technology assessment, participatory policy appraisal and so on, citizens' juries have been proposed as a way of allowing citizens to deliberate on contentious issues

Using a legal-style jury format allows for the panelling of a jury - either as an attempt to provide a representative group of society at large, or as a way of bringing together a marginalized, often unorganized interest group - to discuss a proposal or series of options. The jury is encouraged to crossexamine a series of 'expert witnesses', who present particular positions and evidence. The aim is to come up with a 'verdict', which may or may not be unanimous or consensual; one that represents the 'people's' view (or a particular group's view). The intention is that such a verdict can then feed into wider policy deliberations or campaigning tactics in the broader political arena.

Such an approach was pioneered in the North (see Coote and Lenaghan 1997; Crosby 1996; Wakeford 2002) and has only been recently used in developing-country contexts. Two citizens' juries were held in southern India in 2000 and 2001, and represented important learning opportunities for the development of the approach (Pimbert and Wakeford 2002; Wakeford 2000). The 2001 jury, selected largely from smallholder farmers, many of whom were women, and held in Andhra Pradesh, deliberated on a series of pre-prepared scenarios of future agriculture and rural development for the state, including one scenario based on the state government's 2020 Vision document. The jury rejected this option, putting forward a series of ideals as to what their view for the future might be. This jury process generated much controversy, but also some important reflections on method and approach (IIED 2003; Pimbert and Wakeford 2002). Among these reflections were (from Scoones and Thompson 2003):

- Issues of representation: The need to be clear about whom the jury represents, and how it is chosen. Having an explicit bias towards the poor or marginalized is seen as a legitimate standpoint, but this necessarily has to be regarded as a partial view. But even within such groupings, different people will have (inevitably) different views. It is perhaps this diversity of (sometimes dissenting) opinion that needs to be captured and worked with, rather than assuming that 'the poor' or 'smallholders' necessarily speak with one voice.

- Issues of evidence, legitimacy and authenticity: With views, 'facts' and 
'evidence' so contested, simple arbitration on what is right or wrong is clearly impossible. The process of deliberation itself, whereby alternative framings and understandings are pursued, then becomes key. Diverse views - not just those of mainstream science policy - must be accepted as legitimate and authentic. Through such a process, an 'opening up' (see Stirling, this volume) of debate is encouraged, associated with self-critical reflection on institutional positions and the authority of knowledge.

- Issues of engagement with the political and policy process: One critique of many participatory and deliberative processes is that they are often oneoff 'events', set up by concerned groups within or outside government, but without any explicit linkage to other political or policy processes. Seeking the links between deliberative, informal spaces and more formal arenas - such as representative politics, bureaucratic processes of policy-making or the legal system - is an important challenge. Alternative modes were suggested, including: the use of one-off, high-profile events to raise awareness and shift the tenor of debate in a policy area (the advocacy ideal); attempts at ongoing deliberation with the aim of influencing those in power through inclusive argumentation (the deliberative ideal); and stimulating local organizations and democratic processes to take up the issues raised from the bottom up (the local democratic ideal).

- Issues of accountability and transparency: Designing a process that explicitly seeks to hold government departments, donor agencies and other actors to account, resulting in more responsive policies. The use of 'right-to-information' laws can, for example, be a useful route in ensuring accountability. Yet such consultation mechanisms, such as citizens' juries, can be appropriated and used - like many other participatory processes - to justify actions on the basis that 'the people have been consulted'. The balancing act between being involved and being coopted is a difficult one to judge.

\section{A citizens' jury in Zimbabwe: exploring farming and food futures}

The jury process initiated in Zimbabwe attempted to respond to some of these challenges, while adapting the process to local circumstances - ones that in the period from 2002 proved particularly challenging.

The Izwi ne Tarisiro (translated as 'voice and vision' from the original Shona) process was convened by the Intermediate Technology Development Group (southern Africa), a non-governmental organization (NGO) that had been working in Zimbabwe over the past decade or more. The convening partners were: another NGO, the Biotechnology Trust of Zimbabwe (BTZ); a 